\title{
Theoretical Study of Student's Subjective Initiative in Vocal Music
}

\section{Teaching}

\author{
Chuanzhi Zhong \\ Department of music, Nanchang Normal University
}

Keywords: Vocal Music Teaching; Subjective Initiative; Leading Role

\begin{abstract}
From the perspective of vocal skills, vocal music teaching refers to that vocal teacher teaches ideas and skills of voice production and singing to students. From the characteristics of the subject itself, it is an extremely practical, highly targeted and cooperative, operational subjectivity and non-intuitive subject. Besides, from the perspective of system theory, it treats teacher factor and student factor that affecting student's subjective initiative in vocal music teaching respectively as teacher factor system and student factor system. Focusing on the basis and significance proposed by student's subjective initiative in vocal music teaching, the connotation and constraints of student's subjective initiative, way of realization of student's subjective initiative and other issues, this paper gives a systematical analysis of impact of developing student's subjective initiative on vocal teaching process.
\end{abstract}

\section{Introduction}

Vocal music teaching is an important part of human civilization inheritance activity. From the perspective of vocal skills, vocal music teaching refers to that vocal teacher teaches ideas and skills of voice production and singing to students. From the characteristics of the subject itself, it is an extremely practical, highly targeted and cooperative, operational subjectivity and non-intuitive subject. Under the premise that the author fully affirmed the important role of teachers in vocal music teaching, the author puts forward the concept that developing student's subjective initiative is equally important. Besides, from the perspective of system theory, it treats teacher factor and student factor that affecting student's subjective initiative in vocal music teaching respectively as teacher factor system and student factor system.

How to understand and treat student's subjective initiative is not only an issue on which the entire teaching field has great concern, but also a repeatedly discussed issue in vocal music teaching. Since the seventeenth century, foreign researchers on vocal music theory and vocal music teaching discussed they psychology, emotion and other factors of students learning vocal music. In the nineteenth century, in vocal music learning skills of $A$ complete collection of singing art published by the famous vocal music theory and vocal music pedagogy researcher Garcia, "inner life", "mental state", "thinking", "intention imagination", "control", etc. are mentioned. He believed that thinking was easier than exercise for improving technology. Italian music professor Francesco lamperti pointed out when discussing singing teaching, "A vocal teacher must master three kinds of skills, the teacher should use his strength and knowledge in the aspect of talent, temperament and perception of each student". Following that, some vocal music education theorists emphasized that learners should inspire one's voice with his thinking and nerves. In ancient China, people had recognized that the 
sound of singing was the reflection or manifestation pattern of inner feeling. "The sound is from the heart". (Record of Music) According to a large number of domestic and international vocal works and modern and contemporary researches, vocal learning should focus on student's mental, emotional and other aspects. However, these studies just did analysis on one factor of a teacher or a student, and they did not realize that developing student's subjective initiative of learning vocal music is a complete system. In this system, it includes both teacher factor and student factor, these factors influence each other and interdependent. In this article, the author tries hard to conduct more systematic discussion on developing student's subjective initiative of learning vocal music in vocal music teaching.

The characteristics of vocal music teaching determine the development of subjective initiative of students with thoughts and feelings and unique value creation directly impacts the effect of vocal music teaching. First, whether all the acts of students in vocal music teaching process will accept education as well as degree of understanding and mastery of vocal knowledge and skills, they are not passively accepted, they will be subject to the domination of his own consciousness. Meanwhile, as individual having thoughts and feelings, the student has his own independent personality, he has his own needs, aspirations and dignity. Under vocal music teacher's leading role, influence of vocal music education acts on students in objective form, students accept the educational impact with their active activity, and they continue to internalize external affect in objective form to knowledge, feelings, motivation, attitudes, etc. in subjective form. Secondly, students have selected the vocal knowledge they learned. Based on their previous knowled ge and experience, students often decide to accept what kind of vocal learning method and to sing what type of vocal tracks. Of course, students' learning progress and application of method are associated with their physical and mental development law. For education from the outside, as long as they meet their requirements, they are willing to accept, then, vocal music education can go smoothly. Otherwise, it will be rejected by students, so that the vocal music education lost its role and even fail. Once again, in the process of learning vocal music, students are always disturbed by external environment. In this case, to make students persevere vocal learning and achieve results, the students must through their own hard work and give full play to their initiative.

Focusing on the basis and significance proposed by student's subjective initiative in vocal music teaching, the connotation and constraints of student's subjective initiative, way of realization of student's subjective initiative and other issues, this paper gives a systematical analys is of impact of developing student's subjective initiative on vocal teaching process.

\section{Title}

Vocal music education is the activity that human continue the vocal aesthetic ideas and content, form, skills and creative method of singing, it is an important part of human civilization inheritance. ${ }^{1}$ Vocal teaching refers to vocal music education activities, of which there is specific relation between students and teachers, teaching time, place, stable teaching content, teaching methods. The so-called student's subjective initiative refers to students' subjective awareness and reaction of activities on teaching content, activities and conditions. In vocal music teaching, the meaning of student's subjective initiative mainly includes: First, the student is selective and creative on vocal music knowledge and skills he learned; secondly, student's understanding and mastery degree of vocal knowledge and skills is bound by his subjective factors, such as knowledge, the level of awareness, life experience and learning methods. Student's subjective initiative in vocal music teaching is 
decided by students' independence, development and creativity.

Compared with other teaching activities, vocal music teaching activities has the following advantages: First, it is extremely practical. No matter it is east or west vocal course, theory component is little, most vocal courses are based on one to one teaching model (i.e., one teacher for one student). In recent years, in a number of teacher educations, the form of group lessons, and collective teaching of one to two, one to three or one to many are added, but they are all that teacher sitting at the piano, teacher leads students with piano and teaches students to produce sound and sing. In the course of teaching, teacher corrects student's voice over and over again, sometimes do demonstration. Examination is that students take turns to sing on a stage, teacher sits in the audience seat and gives scoring. Because the vocal itself must be implemented to the students singing, and improvement of singing ability and level needs frequent and repeated practice, and they are associated with all aspects of state (psychological and physiological) of students, just learning theoretical knowledge or participating in distance learning is difficult to learn vocal music well, so it is a highly practical course. Second, it has operational subjectivity and non-intuition. Playing music requires instruments, and vocal music is voice music, in vocal music teaching, musical instrument is the human body itself, the player is also the human body itself, teacher can only teach and guide, he is unable to play, because the instrument is not on teacher's body. So for vocal music teaching, teachers and learners should explore, meditate and study together.

Educational philosophy of an era is often closely linked with the times. In ancient China, the one to one education philosophy of preaching, tuition and disabusing meets the educational needs of the feudal society, it means teachers are supreme and dignity of teaching; the teachers, books, classroom-centered educational philosophy adapts to large-scale industrial production's requirements for skilled workers with necessary knowledge and skills level; the information age of highly developed science and technology requires to educate high-quality builders, it requires us to update educational philosophy and establish people-centered new educational concept. Modern educational philosophy thinks that the student is an active member, he is individual with thoughts and feelings and has unique creative value, and it fully affirmed the subjective initiative of students in the educational process. The process of student's being educated is not simply a transmission process from outside to inside, but also an initiative effect process from inside to outside. In vocal music education practice, although student's change is caused by teacher's intervention, their improvement in skills will be ultimately achieved through their own contradictory movement and determined by the inherent law of this movement.

Chinese education is gradually internationalized, and the requirements for quality of talents to be cultivated by vocal music education are more demanding. Looking at a variety of teaching methods, there is a consensus that vocal music education is not a singer's education. Vocal music education does not take bringing up singer as their responsibility, the primary goal is to educate people, and this is also the starting point and end point for the entire music education. Researchers must be based on people's own development requirements, and pay attention to people's overall development. In layman's terms, it is to realize the comprehensive development of man. Play an integral role of a variety of qualities, which is an integrity requirement of people's quality structure. From the research point of view, all the qualities of people are independent with each other, but from the human development perspective, it is with integrity. Students' activities are often comprehensive reflection of a variety of qualities, and it is often difficult to fulfill task effectively by relying on a single quality. 
Teaching system is a comprehensive body, in which a certain number of interconnected constituent parts (such as teachers, students, teaching content, teaching methods, teaching media and teaching environment, etc.) combine organically with some teaching functions. Teaching and learning are two basic elements of education system, as two sub-systems of education system; teaching and learning are composed of their respective sub-elements. The system of "teaching" includes teachers, subject content, methods, media and other elements; the sub-system of "learning" includes students, learning attitude, learning behavior, degree of awareness and other factors. Vocal music teaching is also the interaction and unify of two large systems of teachers' teaching and students' learning. Vocal music teaching is a very practical teaching; it has big difference from other subjects. It is educational activities that develop and train students to master singing skills and techniques, develop students' feeling for music and art, expression and creativity, and develop students' noble artistic sentiments. In vocal learning process, students' psychological elements, namely the psychological feeling and thinking activities are in the active position. Because vocal music is trained for feeling, that is "inner hearing", "inner vision". Students need to hear resonance sound in their cavity, not just listen to the sound outside their body. If the feeling of inner hearing is insensitive, it is difficult to find resonance position. "Inner vision" refers to that when students sing; students should "see" bright timbre inside the cavity and empty dark tone in resonance cavity. In addition to students' "feeling", it is the image thinking in the brain, it is the command to direct and adjust. If a student want to learn vocal music well, having a good voice is not enough; you had to have a good brain. For example, when breathing into one's belly, the routes of breath sinking and upturning, the expansion and opening degree of the resonance cavity, direction of sonic transmission and reflection, coordination of relaxation and tension and so on, all of which have to rely on "image thinking" to adjust and balance. Thus, in vocal music teaching, it is critical to develop student's subjective initiative. In this chapter, the author tries to analyze on developing student's subjective initiative from both teachers and students. Factors of teachers and students are relatively independent and intertwined to form a complex teaching system.

Education philosophy is the reflection of the comprehensive quality of a teacher; it is comprehensive reflection of knowledge level, theoretical training and practical experience of a teacher. Different ideas lead to different behavior and behavioral outco mes. Education philosophy decides teachers' teaching attitude, the way, method, use of means and realization of teaching effect. As "engineers of human souls", teachers bear the mission of inheritance and development of human culture, train the next generation and guide people to science and civilization.

As a teaching of strong teaching skills and techniques, vocal music teaching puts forward a very high demand for teachers' professional quality structure, i.e. vocal singing, vocal music theory knowledge and vocal artistic culture. "Singing" is the least basic skill that vocal teacher should have, and it is exemplary and inspiring in vocal music teaching. A good vocal performance artist may not necessarily be a good vocal music teacher, but a good vocal teacher should first be an excellent vocal singer. Therefore, teachers are required to do accurate singing, vivid and moving, through artistic appeal of the song to stimulate student's interest in learning, stimulate student's initiative and enthusiasm in learning. Meanwhile, teacher's vocal theoretical level and level of artistic cultivation are also essential for vocal music teaching.

Ability is the skill or psychological characteristics that people effectively complete certain activity. The ability is always linked with activities; it is the reflection of knowledge and experience in practice. There are links and differences between ability and knowledge. A vocal teacher only has 
extensive and profound vocal knowledge and singing skills may not be able to do his job well, he must also have corresponding teaching ability. Vocal music teaching is both a science and an art. The Chinese well-known educationalist Ren Gan (1905 - 1982) thought that "Education is the most profound and most complex art", "Teaching of outstanding teachers is like people enjoy famous painting or music, they forget tiredness, and can be unconsciously influenced".

The education object of a vocal music teacher faces individuals with different characters, interests, cultures and qualities, they are real people whose thoughts and feelings are changing anytime and anywhere, whether it is from physical aspect or from psychological aspect, or whether it is from cognitive factors or from emotional factors, and students are an organic whole. In modern era, while scientific development continues to divide, it also presents the trend towards integration, ideas and theories of all the disciplines are interpenetrating, horizontal linkage between disciplines continues to strengthen, coupled with joint of vocal art and other related disciplines and sister art, if vocal teacher wants to thoroughly explain and analyze vocal knowledge, he must have relatively comprehensive and systematic cultural quality, to borrow related knowledge of other disciplines. Therefore, vocal teachers need to have cultural knowledge of pedagogy, psychology, physiology, literature, aesthetics, acoustics, phonetics, and dance, sculpture, painting, film, theater and other related aspects of sister arts. Absorbing nutrients from various disciplines and put the knowledge to infiltrate and contact between disciplines. Only reading all-round knowledge extensively, vocal teachers can master professional knowledge of the discipline.

On the definition of intelligence, so far there is no consensus. There are several more popular definitions of intelligence at home and abroad: 1 , intelligence is the cognitive ability; 2 , intelligence is the potential ability to learn; 3 , intelligence is the ability of abstract thinking; 4 , intelligence is the ability to create new things; 5 , intelligence is the ability to adapt to new situations; 6 , intelligence is the ability to analyze problems and problem-solving; 7, intelligence is IQ in intelligence tests. At present, in China's psychology, more people tend to think that intelligence is general cognitive ability. It is the comprehensive cognitive ability consists of a variety of psychological components of observation, memory, thinking, imagination, language ability, skills, etc. And this comprehensive cognitive ability is enough to ensure people to carry out cognitive activities effectively. Therefore, intelligence is the condition or weapon to acquire knowledge, knowledge is the basis or tool for the development of intelligence.

Famous American scholar Arnheim said, "Intuition and intellect are two cognitive processes." 1 The intellect here is quite with the intelligence I said earlier. Some educators believe that the only way to gain knowledge is the way of intellect, while intuition does not cause enough attention. Intuition is considered a few individuals' mysterious, innate talent, it is difficult to get through education. In fact, intuition is not a few individuals' qualities, intuition and intellect constitute our whole soul, and it is the basic and indispensable one of the two aspects of understanding. Both aspects support all the productive learning activities in all areas of knowledge, without the help of anyone, the other is not perfect.

The word personality comes from the Latin, it originally refers to the mask an actor wears, later it was extended to inner life manifested by a person's behavior patterns on the stage, becoming the issue studied together by philosophy, sociology, law, psychology, education, theory of literature and other disciplines. Psychology and pedagogy generally believe that personality is the sum of various characteristics of certain consciousness tendency, i.e. the whole mental outlook that a person is different from other people. Personality formation and development is very complex, biological 
factors (i.e. inherited physiological characteristics), environmental factors, age factors and other factors intertwined together and act together. These factors and relationship between these factors are not identical, so each person's personality reflects his own unique mental state. In Chunqiu period, educator Confucius proposed the famous view of "Sex close, habit far apart". The reason why people vary widely in the world depends largely on the different personalities. Personality consists of three main components: individual consciousness tendentiousness, individual psychological characteristics and self-awareness system. Among the three components, individual tendentiousness mainly includes needs, motivations, interests, ideals, beliefs and worldview. Individual psychological characteristics mainly include ability, temperament and personality, self-awareness refers to a person's understanding of himself and his relationship with the things around. All the practice activities are the activities that people participate in, and they are all carried out under the regulation of personality.

Vocal music teaching is a very active "bilateral" activity, it is a kind of skill-practice based teaching, the entire teaching process is completed under the guidance of teacher, teacher mobilizes and inspires students to actively participate and practice. A great singer may not necessarily be a high level vocal music teacher; a person with special good voice is not necessarily a good vocal music student. The reason is that they are not necessarily good at "teaching" and "learning". Only when those teachers teach clever, scholars also learn smart, it can give full play to the initiative of students, to maximize excavate the potential of students, teaching effect will be remarkable.

\section{Conclusions}

From the basis and significance proposed by student's subjective initiative in vocal music teaching, the connotation and constraints of student's subjective initiative, way of realization of student's subjective initiative and other issues, this paper gives a system analysis of impact of developing student's subjective initiative on vocal teaching process. The aim is to systematically research the issue of student's subjective initiative in vocal music teaching, correctly understand and deal with all kinds of contradictions in vocal music teaching, improve the quality of vocal music teaching, and train high-quality vocal talents.

\section{Acknowledgements}

Jiangxi province colleges and universities teaching reform research topic: "in Jiangxi Province, the study plan of rural primary and secondary school music teachers training backbone"(No JXJG-14-23-7 ),

\section{References}

[1] Jørgensen H. Student learning in higher instrumental education: who is responsible?[J]. British Journal of Music Education, 2000, 17(01): 67-77.

[2] Cheon J, Lee S, Crooks S M, et al. An investigation of mobile learning readiness in higher education based on the theory of planned behavior[J]. Computers \& Education, 2012, 59(3): 1054-1064.

[3] Stanley M, Brooker R, Gilbert R. Examiner perceptions of using criteria in music performance assessment[J]. Research Studies in Music Education, 2002, 18(1): 46-56. 
[4] Berkley R. Teaching composing as creative problem solving: Conceptualising composing pedagogy[J]. British Journal of Music Education, 2004, 21(03): 239-263.

[5] McPherson G E, Hendricks K S. Students' motivation to study music: The United States of America[J]. Research Studies in Music Education, 2010, 32(2): 201-213.

[6] Benner C H. Teaching performing groups[C]. Music Educators National Conference, 1972.

[7] Dickey M. The impact of web-logs (blogs) on student perceptions of isolation and alienation in a web-based distance-learning environment[J]. Open Learning, 2004, 19(3): 279-291.

[8] Dixson A D, Rousseau C K. And Researchers are still not saved: Critical race theory in education ten years later[J]. Race ethnicity and education, 2005, 8(1): 7-27.

[9] Colwell R J, Beall G H. Program Evaluation in Music Teacher Education [with Response][J]. Bulletin of the Council for Research in Music Education, 1985: 18-64.

[10] Humphreys M, Hyland T. Theory, Practice and Performance in Teaching: professionalism, intuition, and jazz[J]. Educational Studies, 2002, 28(1): 5-15.

[11] Turino T. Nationalism and Latin American music: Selected case studies and theoretical considerations[J]. Latin American Music Review, 2003, 24(2): 169-209. 